\title{
Structural changes in the lacrimal sac epithelium and associated lymphoid tissue during experimental dacryocystitis
}

This article was published in the following Dove Press journal:

Clinical Ophthalmology

28 October 2011

Number of times this article has been viewed

\author{
Makoto Ishikawa' \\ Masabumi Kubo² \\ Seiji Maeda ${ }^{3}$ \\ Yu Sawada' \\ Eiichi Uchio ${ }^{4}$ \\ Takeshi Yoshitomi' \\ 'Department of Ophthalmology, \\ Akita University School of Medicine, \\ Akita, Japan; ${ }^{2}$ Fukiage Eye Clinic, \\ Hachinohe, Japan; ${ }^{3}$ Maeda Eye \\ Clinic, Honjo, Japan; ${ }^{4}$ Department \\ of Ophthalmology, Fukuoka University \\ School of Medicine, Fukuoka, Japan
}

Purpose: To examine structural changes in the lacrimal sac epithelium and associated lymphoid tissue of rabbits with experimentally induced dacryocystitis.

Methods: Experimental dacryocystitis was induced by an inoculation of Staphylococcus aureus into the lacrimal sac. The histological changes of the inflamed lacrimal sac epithelium and associated lymphoid tissue were studied by light and electron microscopy.

Results: After 1 month, numerous inflammatory cells (CD20-positive B lymphocytes, CD3-positive T lymphocytes, IgA-positive plasma cells, and polymorphonuclear leukocytes) infiltrated the lamina propria and the epithelium overlying the diffuse lymphoid tissue. Three months later, the density of the infiltrated leukocytes was markedly decreased. The epithelial lining overlying the diffuse lymphoid tissue became thicker with numerous secretory granules in the supranuclear regions.

Conclusion: The lacrimal sac epithelium and associated lymphoid tissue play a major role in the defense mechanism during inflammation. Overproduction of secretory granules after bacterial inoculation could enhance the antimicrobial defense.

Keywords: experimental dacryocystitis, lacrimal sac epithelium, lymphoid tissue, structure, rabbit

\section{Introduction}

The ocular surface is constantly in contact with environmental microorganisms and hence is vulnerable to infection. The flow of tears carries foreign materials and antigens into the lacrimal drainage system where the lacrimal sac mucosa has a variety of anti-infection strategies to prevent colonization by microorganisms. ${ }^{1-7}$ The first line of defense against invading pathogens is the lacrimal sac epithelium. ${ }^{2,8}$ The epithelial cells covering the inner surface are tightly bound together by junctional complexes and protect the underlying tissues from viral or bacterial invasion. The epithelial cells secrete $\operatorname{IgA},{ }^{2}$ anti-infection peptides, ${ }^{6}$ and mucins. ${ }^{7}$ Many pathological conditions can cause structural changes in the mucosa, including hyperplasia of the goblet cells. ${ }^{8}$ A second line of defense, which is integrated with the activities of the epithelium, is the lacrimal drainage-associated lymphoid tissue (LDALT). ${ }^{9}$ The LDALT constitutes a part of the mucosa-associated lymphoid tissue (MALT). ${ }^{10,11}$ These defense mechanisms prevent attacks from bacteria that could lead to dacryocystitis.

Dacryocystitis is the most frequent result of infections in the efferent lacrimal drainage system. It arises because of obstruction of the lacrimal duct, pooling of tears in the lacrimal sac, and subsequent infection. ${ }^{12}$ However, the pathogenesis is still not completely known. In an effort to clarify this etiological uncertainty, we established a
Correspondence: Makoto Ishikawa Department of Ophthalmology, Akita University School of Medicine, Akita 010-8543, Japan

Tel +8 I 018834 I I I I ext 3472

Fax +810188362621

Email mako@med.akita-u.ac.jp 
model of dacryocystitis in rabbits. ${ }^{13}$ In the present study, we used the model to examine structural changes in the rabbit lacrimal sac epithelium and the associated LDALT.

\section{Materials and methods}

Fifteen male Japanese white rabbits, each weighing about $2.0 \mathrm{~kg}$, were used in this study. The rabbits were maintained in accordance with the Association for Research in Vision and Ophthalmology statement on the care and use of animals in ophthalmic research.

\section{Induction of experimental dacryocystitis}

Experimental dacryocystitis was induced using our previously described methods. ${ }^{13}$ Briefly, 2.5\% purified egg white albumin was emulsified in complete Freund's adjuvant and injected subcutaneously into the backs of the 15 rabbits $(1.0 \mathrm{~mL} / \mathrm{rab}$ bit). An additional adjuvant, inactivated Bordetella pertussis, was injected intravenously (1010 cells/rabbit). After 4 weeks, the inactivated $B$. pertussis (1010 cells/rabbit, $0.1 \mathrm{~mL}$ ) was injected into the right and left lacrimal sacs through the lacrimal punctum. Immediately after the $B$. pertussis injection into the lacrimal sacs, Staphylococcus aureus (ATCC25923), grown at $37^{\circ} \mathrm{C}$ and suspended in $0.3 \mathrm{~mL}$ saline (107 cells/ $\mathrm{mL}$ ), was injected into the right lacrimal sac via the lacrimal punctum. The left lacrimal sac was injected with purified egg white albumin and served as the control.

\section{Histological procedures}

The rabbits were euthanized by an overdose of ketamine injected into a marginal ear vein at 1 or 3 months after infection. The lacrimal sacs were removed, dissected in chilled saline, and fixed in $10 \%$ formalin in $0.1 \mathrm{M}$ phosphate buffer ( $\mathrm{pH} 7.4$ ) for 24 hours. The specimens were then embedded in paraffin, and $10 \mu \mathrm{m}$ sections were cut. The sections were stained with hematoxylin-eosin for light microscopy.

For electron microscopy, the lacrimal sacs were fixed with $2.5 \%$ glutaraldehyde in $0.1 \mathrm{M}$ phosphate buffer ( $\mathrm{pH} 7.4$ ) for 2 hours. After postfixation with 1.0\% osmium tetroxide in the same buffer, they were dehydrated and then embedded in epoxy resin. Ultrathin sections were prepared with a diamond knife on the MT-II ultramicrotome (Du Pont, Newtown, CT) and examined with an H-700 electron microscope (Hitachi, Ltd, Tokyo, Japan).

\section{Immunohistochemistry}

For immunohistochemistry, lacrimal sacs were fixed with $1 \%$ paraformaldehyde in $0.1 \mathrm{M}$ phosphate buffer for 1 hour at $4^{\circ} \mathrm{C}(\mathrm{n}=5$ animals per experiment group).
They were then embedded in optimal cutting temperature compound (Sakura Global Holdings, Tokyo, Japan) and frozen with liquid nitrogen. Cryosections were incubated with mouse antihuman CD20 monoclonal antibody (1:100; DakoCytomation, Grostrup, Denmark) and mouse antihuman IgA monoclonal antibody (1:100; DakoCytomation) to identify B lymphocytes and plasma cells, respectively. The same sections were also incubated with rabbit antihuman CD3 antibody (1:100; Sigma-Aldrich, St Louis, MO) to colocalize T lymphocytes. Rhodamine-conjugated goat antimouse IgG (1:200; ZYMED Laboratories, San Francisco, CA) or fluorescein isothiocyanate (FITC)-conjugated goat antirabbit IgG (1:200; ZYMED Laboratories) was applied to the frozen sections as a secondary antibody. Binding sites of IgGs were detected by confocal laser scanning microscopy (LSM510 Axiovert200M; Carl Zeiss Meditec, Göttingen, Germany). Diamidino-2-phenylindole (DAPI) was used for nuclear staining. In other cryosections, horseradish peroxidase (HRP)-conjugated goat antimouse IgG (1:200; ZYMED Laboratories) was applied to the frozen sections as a secondary antibody.

\section{Quantitative analysis of images obtained by light and electron microscopy}

ImageJ 1.34 (National Institutes of Health, Bethesda, MD) software was used for image processing. We picked five light micrographs for each experiment. In each section, the number of the inflammatory cells located in the epithelium and lamina propria was counted at three different locations, and the density of cells per $100 \mu \mathrm{m}^{2}$ was calculated. Densities of secretory granules were calculated per epithelial cell in ten electron micrographs at each experimental condition. Statistical significance was determined by two-sided Student's $t$-test, and $P$ values less than 0.05 were considered significant.

\section{Results}

\section{Structure of the control lacrimal sac}

In control lacrimal sacs, the LDALT comprised both nodular and diffuse lymphoid tissue (Figure 1A). A flattened follicleassociated epithelium (FAE) covered the lymphoid follicle (Figure 1B). In the nodular lymphoid tissue, numerous lymphocytes were aggregated. The epithelial layer of the lacrimal sac had a columnar pseudostratified appearance, and the epithelial cells contained a few secretory granules. There were no goblet cells present (Figure $1 \mathrm{C}$ and D). A number of inflammatory cells were located in the vicinity of the basal epithelial layer and the lamina propria (Figure 1D). 


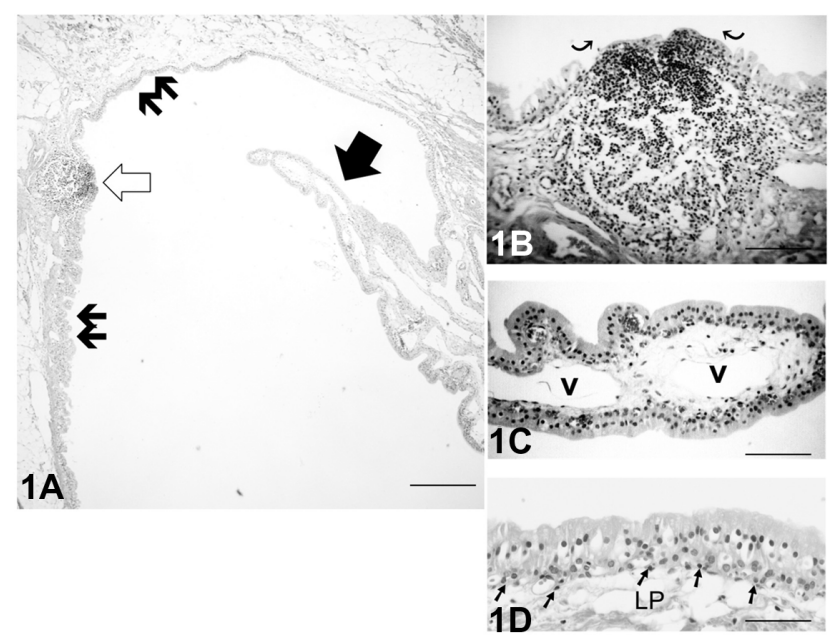

Figure I (A) Light micrograph of the hematoxylin-eosin stained control left lacrimal sac without Staphylococcus aureus inoculation. A mucosal process (solid arrow) extended into the lumen, and an organized lymphoid follicle (open arrow) was present. The lacrimal drainage-associated lymphoid tissue comprised diffuse (double arrows) and nodular lymphoid tissue. Bar $=100 \mu \mathrm{m}$. (B) At greater magnification, the follicle in Figure IA showed the flattened cells of the follicleassociated epithelium (curved arrows) covering the central portion of the follicle. Bar $=60 \mu \mathrm{m}$. (C) At higher magnification of a mucosal process the blood vessels ( $v$ ) in the lamina propria (LP) were apparent. There were no goblet cells present in the epithelial layer. Bar $=50 \mu \mathrm{m}$. (D) The epithelial layer of the lacrimal sac had a columnar pseudostratified appearance, and there were no goblet cells present. Lymphocytes (arrows) were distributed in the vicinity of the basal layer of the epithelium. Bar $=40 \mu \mathrm{m}$.

\section{S. aureus-induced dacryocystitis}

Three of the 15 rabbits did not develop acute dacryocystitis after $S$. aureus inoculation into the lacrimal sac. The remaining twelve rabbits developed acute dacryocystitis with swelling and redness in the lacrimal sac region by 1 month after inoculation. Five of these were euthanized at that time, and the lacrimal sacs were extirpated. Dacryocystitis persisted for 3 months in the remaining seven rabbits. These seven rabbits experienced loss of hair in the lacrimal sac region (Figure 2A), and upon application of pressure a mucopurulent material was regurgitated onto the ocular surface (Figure 2B). Control lacrimal sacs without $S$. aureus inoculation did not develop inflammation.
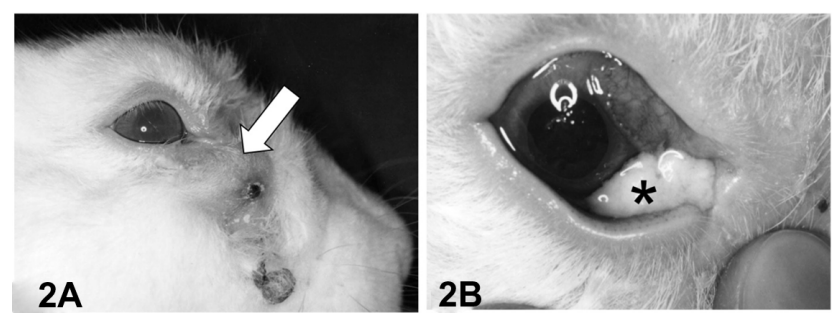

Figure 2 Lateral view of rabbit with dacryocystitis 3 months after Staphylococcus aureus inoculation. (A) The lacrimal sac was distended (white arrow) and the skin covering the sac exhibited depilation. (B) Pressure applied to the swollen area resulted in expression of mucopurulent contents (*) onto the ocular surface.

\section{Light microscopic examination}

\section{of S. aureus-induced dacryocystitis}

Nodular lymphoid tissue

One month after $S$. aureus inoculation, nodular inflammatory cells were present in the lamina propria of the lacrimal sac (Figure 3A), and the epithelial cells had varying degrees of inflammatory cell invasion (Figure 3B). There was also some desquamation of the degenerated epithelial cells that covered the follicle. Three months later, the epithelial lining covering the nodular lymphoid tissue was intact, and the infiltration of the inflammatory cells decreased (Figure 3C).

\section{Diffuse lymphoid tissue}

One month after $S$. aureus inoculation, there were numerous inflammatory cells in the lacrimal sac epithelium and lamina propria (Figure $4 \mathrm{~A}-\mathrm{C}$ ). There were also degenerated cells that had desquamated from the epithelium (Figure 4B). The lamina propria was thicker than in the controls, possibly due to the presence of the inflammatory cells (Figure 4A-C).

Three months after S. aureus inoculation, fewer inflammatory leukocytes remained diffusely distributed in the epithelium and lamina propria (Figure 4D-F). A number of light cells (Figure 4E) and goblet cells (Figure 4F) were present in the epithelial layer. The thickness of the lamina propria was thinner compared with 1 month after inoculation.

\section{Electron microscopic examination}

Nodular lymphoid tissue in lacrimal sac with S. aureus-induced dacryocystitis

One month after $S$. aureus inoculation, the FAE contained cored secretory granules (Figure 5A). Numerous plasma cells and lymphocytes, some of which were apoptotic, were

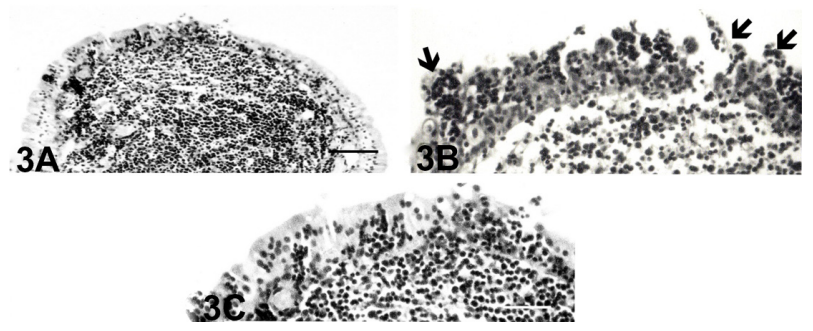

Figure 3 Light micrographs of nodular lymphoid tissue in the inflamed lacrimal sac at I month (A) and (B) and 3 months (C) after Staphylococcus aureus inoculation. (A) One month after bacterial inoculation, the nodular lymphoid tissue had numerous lymphocytes, and many were infiltrated into thefollicle-associated epithelium. Bar $=60 \mu \mathrm{m}$. (B) There was infiltration of the inflammatory cells and desquamation of the degenerated epithelial cells (arrows) that covered the follicle. Bar $=40 \mu \mathrm{m}$. (C) At 3 months, the follicle-associated epithelium was intact, but the epithelial infiltration of the lymphocytes decreased. Bar $=40 \mu \mathrm{m}$. 


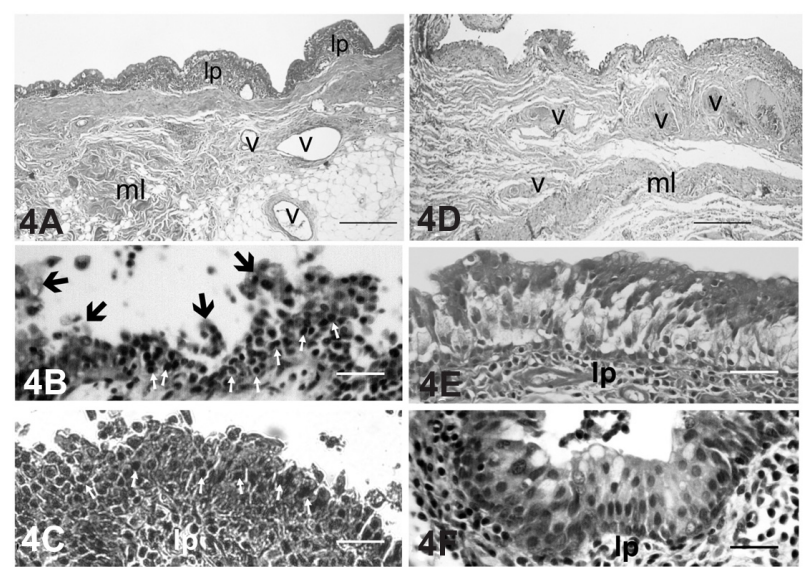

Figure 4 Low magnification light micrographs of the inflamed lacrimal sac I month (A-C) and 3 months (D-F) after Staphylococcus aureus inoculation. (A) One month after inoculation, numerous inflammatory cells (see panels $B$ and $C$ ) were infiltrated into the lamina propria (IP) located between the overlying epithelium and the underlying muscle layer $(\mathrm{ml})$. The presence of these cells markedly increased the thickness of the lamina propria compared with that at 3 months after inoculation (see panel D). Bar $=80 \mu \mathrm{m}$. (B) Numerous inflammatory leukocytes were infiltrated into the epithelial layer of the lacrimal sac mucosa (small arrows). There was abundant desquamation of degenerated epithelial cells (large arrows). Bar $=25 \mu \mathrm{m}$. (C) In another portion of the inflamed lacrimal sac, leukocytes were accumulated in the LP, and some of them had infiltrated in the epithelium (arrows). Bar $=25 \mu \mathrm{m}$. (D) Three months after S. aureus inoculation, infiltration of the inflammatory cells in the LP was markedly decreased compared with that at I month. Consequently, the LP was visibly reduced in thickness. Bar $=80 \mu \mathrm{m}$. (E) Numerous inflammatory leukocytes remained in the LP. Epithelial cells with clear cytoplasm (light cells) were found in the middle to basal layers. Bar $=25 \mu \mathrm{m}$. (F) In another portion of the inflamed lacrimal sac, the epithelial layer was composed of stratified columnar cells with mucus droplets at the apical region, which gave them the appearance of goblet-like cells. Some leukocytes remained in the LP. Bar $=25 \mu \mathrm{m}$.

Abbreviation: v, blood vessel.

present in the nodular lymphoid tissue (Figure 5B). Three months later, there was a marked accumulation of secretory granules with distinct cores in the FAE (Figure 5C), and there were also numerous plasma cells and polymorphonuclear lymphocytes (Figure 5D).

\section{Diffuse lymphoid tissue in lacrimal sac} with S. aureus-induced dacryocystitis

One month after $S$. aureus inoculation, necrotic epithelial cells were distributed within the epithelium (Figure 6A). The intact epithelial cells had numerous cored secretory granules in the apical portions. Abundant lymphocytes and polymorphonuclear leukocytes were infiltrated into the lamina propria and epithelial layer (Figure 6A and B). High endothelial venules (HEVs, Figure 6C) and dendritic cells (Figure 6D) were present in the lamina propria. Along with the lymphocytes, there were also plasma cells in the lamina propria (Figure 6C and E).

Three months after $S$. aureus inoculation, the stratified columnar epithelium was three to four cells deep, and the
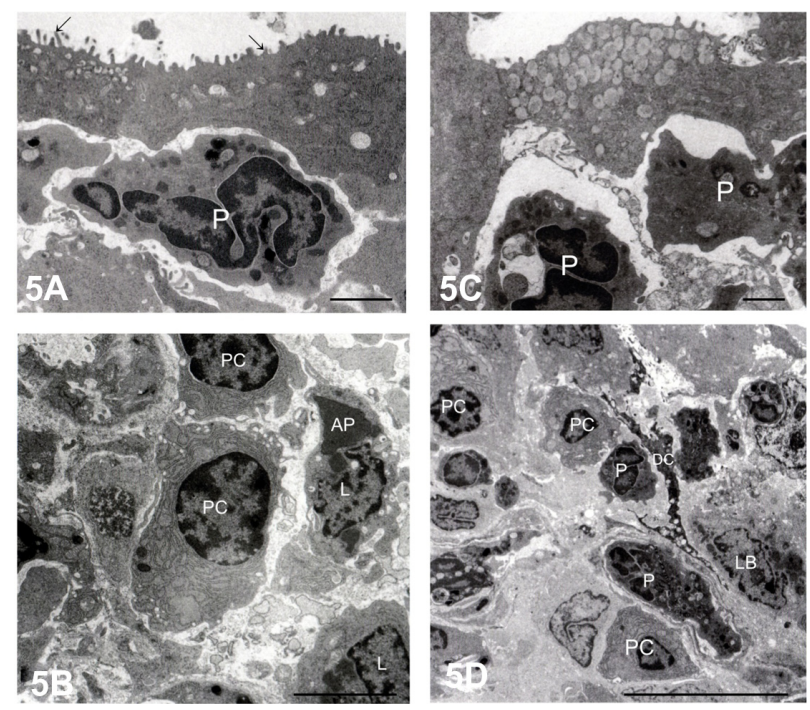

Figure 5 Electron micrographs of nodular lymphoid tissue at I month (A and $\mathbf{B}$ ) and 3 months (C and D) after Staphylococcus aureus inoculation. (A) Polymorphonuclear leukocytes $(\mathrm{P})$ were situated beneath the flattened follicle-associated epithelium, which contained microvilli (arrows). Bar $=2 \mu \mathrm{m}$. (B) The center of the follicle was occupied by densely packed lymphocytes (L) and plasma cells (PC). Bar $=2 \mu \mathrm{m}$. (C) At 3 months after inoculation, the follicle-associated epithelium contained numerous secretory granules, each with an electron-dense core. Bar $=2 \mu \mathrm{m}$. (D) PC and P were present in the center of the follicle. A dendritic cell (DC) was adjacent to the inflammatory cells. Bar $=2 \mu \mathrm{m}$.

Abbreviation: AP, apoptotic lymphocyte.

apical layer was composed of a mixture of light and dark cells (Figure 7A-C). The dark cells contained apically located secretory granules. There appeared to be an increase in the number of cored secretory granules compared with the specimens at 1 month after bacterial inoculation. The dark cells had well-developed microvilli that were embedded in the surrounding apical extracellular matrix (Figure 7D and $\mathrm{E}$ ). In contrast, there were only rudimentary microvilli without any extracellular matrix on the apical surface of the light cells (Figure 7D and F).

At 3 months after inoculation, the number of the infiltrated inflammatory cells was diminished compared with that at 1 month. The HEVs (Figure 7G) and plasma cells (Figure 7H) remained, but there were more collagen fibers and fibrocytes (Figure 7I) in the lamina propria compared with 1 month after inoculation.

\section{Quantitative analysis of results obtained by light and electron microscopy}

The density of infiltrated inflammatory cells in both the epithelium and lamina propria was highest 1 month after $S$. aureus inoculation (Table 1). By 3 months, the density was significantly lower but still elevated compared with the control lacrimal sacs. 


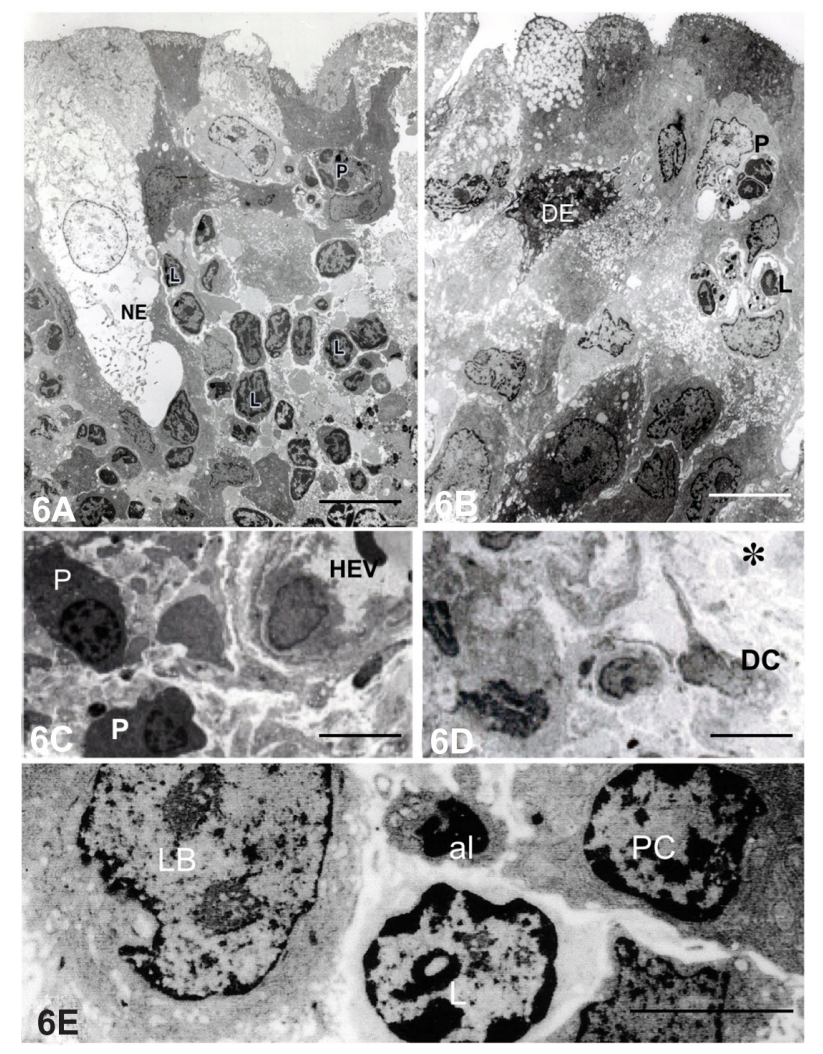

Figure 6 Electron micrographs of diffuse lacrimal sac lymphoid tissue I month after Staphylococcus aureus inoculation. (A) Polymorphonuclear leukocytes (P) and lymphocytes $(\mathrm{L})$ were present in the epithelium. Bar $=7 \mu \mathrm{m}$. (B) Secretory granules were present in the apical portion of the epithelial cells. Bar $=7 \mu \mathrm{m}$. (C) Plasma cells (PC) were situated in the connective tissue stroma. Bar $=12 \mu \mathrm{m}$. (D) A dendritic cell (DC) situated among collagen fibers $(*)$. Bar $=10 \mu \mathrm{m}$. (E) High magnification of the aggregated lymphoblasts (LB), L, and PC in the lamina propria. An apoptotic lymphocyte (AP) was also present. Bar $=2 \mu \mathrm{m}$.

Abbreviations: DE, degenerated epithelial cell; HEV, high endothelial venule; $\mathrm{NE}$, necrotic epithelial cell.

The density of the secretory granules in the dark cells of the epithelium was significantly elevated compared with controls after 1 month (Table 2). Three months after inoculation, the density of epithelial granules increased further and was significantly greater than at 1 month after inoculation.

\section{Immunohistochemistry}

In the nodular lymphoid tissue, CD20-positive B lymphocytes were accumulated in the center of lymphoid follicle 1 month after inoculation (Figure 8A). Some of these cells had infiltrated into the surrounding diffuse lymphoid tissue. At the same time, IgA-positive plasma cells were diffusely distributed in the lacrimal sac epithelium and lamina propria (Figure $8 \mathrm{~B}$ ). The density of these cells was decreased 3 months after inoculation (Figure 8C).

In control lacrima sacs, there were few CD20- and CD3-lymphocytes in the lamina propria (Figure 9A-C).
At 1 month after inoculation, numerous CD20-positive lymphocytes were distributed predominantly in the lamina propria, though some were present in the epithelium (Figure 9D and F). At the same time, many CD3-positive lymphocytes were infiltrated into the lacrimal sac epithelium and lamina propria (Figure 9E and F). Three months after inoculation, there were fewer CD20-positive lymphocytes in the lamina propria (Figure 9G and I); however they remained in greater density than the controls. At that time, there were many fewer CD3-positive lymphocytes in the lamina propria (Figure 9H and I).

\section{Discussion}

We have established an experimental rabbit dacryocystitis model of chronic $S$. aureus infection. ${ }^{13}$ In the present study, we used the model to demonstrate structural changes of the lacrimal sac epithelium and the LDALT in response to bacterial infection. One month after $S$. aureus inoculation, the epithelium and lamina propria of the lacrimal sac were characterized by the prominent invasion of CD3- and CD20-positive lymphocytes, IgA-positive plasma cells, and polymorphonuclear leukocytes. A resulting inflammatory immune response with the production of cytokines and proteases is likely to have occurred and may have led to epithelial destruction. ${ }^{14,15}$ Three months after inoculation, the inflammatory cells had diminished, and secretion by the epithelium may have been more activated as judged by the presence of secretory granules in the supranuclear region of the dark cells in the epithelium compared with 1 month. There were more collagen fibers and fibrocytes in the lamina propria compared with 1 month. These results indicate that the lacrimal sac epithelium and the LDALT play a major role in defense mechanism against microorganisms during the inflammatory process.

LDALT is divided into two forms. In one, the lymphocytes are organized into the nodular lymphoid tissue, and in the other the lymphocytes are diffusely distributed. ${ }^{12}$ The nodular lymphoid tissue represents the afferent arm of mucosal immunity where antigens are taken up from the environment by the specialized FAE. ${ }^{13}$ Antigens are then presented to lymphocytes by antigen-presenting dendritic cells. In the present study, the FAE showed varying degrees of inflammatory cell invasion after bacterial inoculation, whereas the structure of the nodular lymphoid tissues was maintained during the chronic experimental inflammation. The diffuse form of lymphoid tissue, in contrast, is perceived as the efferent arm of mucosal immunity. 


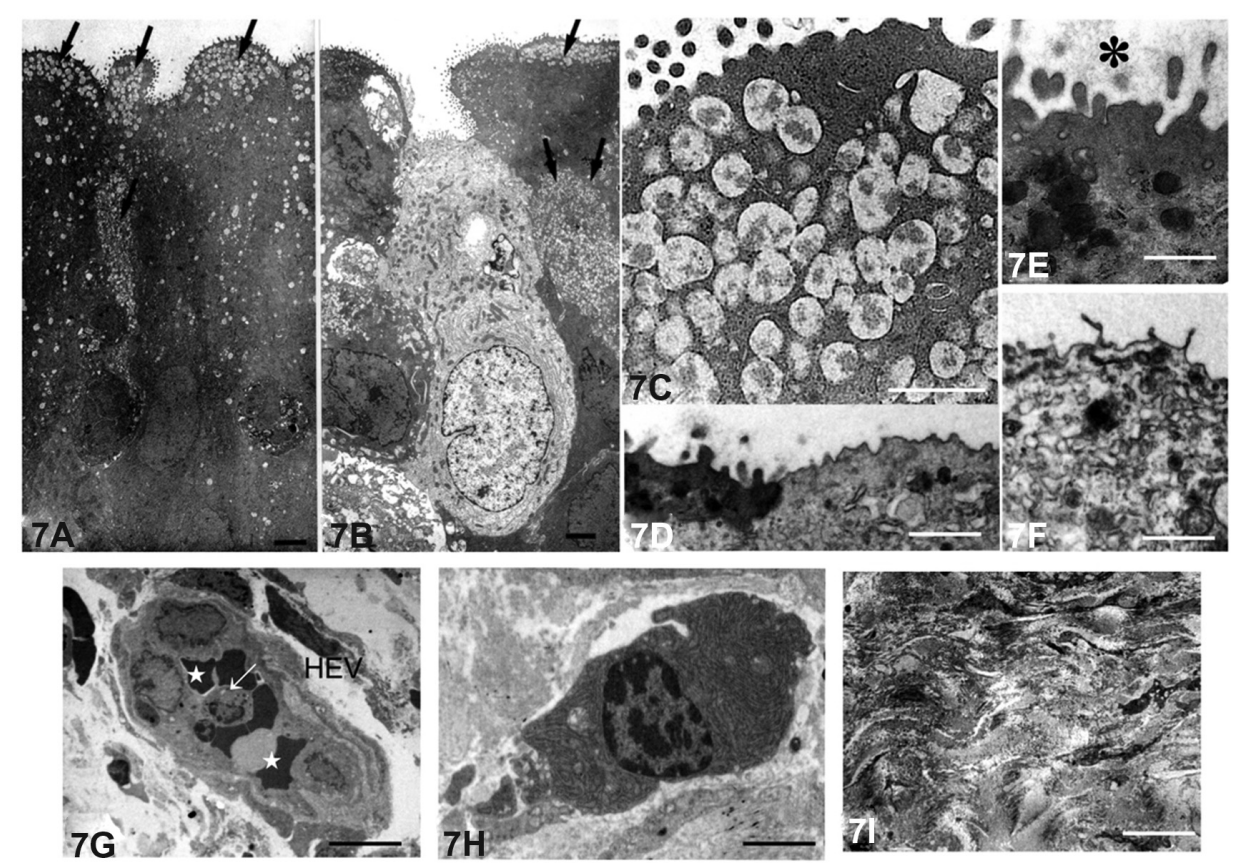

Figure 7 Electron micrographs of lacrimal sac epithelium and diffuse lymphoid tissue 3 months after Staphylococcus aureus inoculation. (A-F) Lacrimal sac epithelium. (A) The superficial epithelial cells were columnar and had accumulations of secretory granules (arrows) in the apical region of the dark epithelial cells. Bar $=3 \mu \mathrm{m}$. (B) Light cells were also present in the epithelium among the dark cells (arrows, secretory granules in dark cells). Bar $=3 \mu \mathrm{m}$. (C) The cored secretory granule aggregated in the apical region of the dark epithelial cells. Bar $=I \mu \mathrm{m}$. (D) Microvilli were present on the apical region of the dark cells, whereas on the light cells they were poorly developed. Bar $=6 \mu \mathrm{m}$ (E) The microvilli of the dark cells were embedded in an extracellular matrix (*). Bar $=1 \mu \mathrm{m}$. (F) Rudimentary microvilli were sparsely distributed on the light cells (arrows). $\mathrm{Bar}=\mathrm{I} \mu \mathrm{m}$. (G-I) Inflamed diffuse lymphoid tissue in the lamina propria. (G) High endothelial venules (HEV) were present in the lamina propria. Leukocytes (arrow) and the erythrocytes (stars) were in contact with endothelial cells. Bar $=I \mu \mathrm{m}$. $(\mathbf{H}) \mathrm{A}$ small number of the plasma cells were present in the connective tissue. Bar $=0.3 \mu \mathrm{m}$. (I) Collagen fibers and fibrocytes were arranged transversely in the lamina propria. Bar $=1 \mu \mathrm{m}$.

The present study demonstrated the remarkable changes of effector components of the mucosal immune system such as CD20-positive B lymphocytes, CD3-positive T lymphocytes, IgA-positive plasma cells, and polymorphonuclear leukocytes after bacterial inoculation. These findings indicate that the lacrimal sac is protected from pathogens by the local immune system present in the form of the LDALT.

Chronic dacryocystitis is characterized by overproduction of the mucopurulent substances from the lacrimal sac epithelium. Dacryocystorhinostomy tissue samples of Mauriello et $\mathrm{al}^{8}$ revealed an increased amount of mucous secretion accompanied by significantly increased numbers

Table I Density of infiltrated lymphocytes, plasma cells, and polymorphonuclear leukocytes in the lacrimal sac epithelial layer and lamina propria. Contralateral lacrimal sacs not injected with Staphylococcus aureus served as controls

\begin{tabular}{lc}
\hline Condition & Density (cells per $\left.100 \mu \mathbf{m}^{2}\right)$ \\
\hline Control & $25.8 \pm 7.8$ \\
I month after inoculation & $252.5 \pm 36.3^{\mathrm{a}, \mathrm{b}}$ \\
3 months after inoculation & $156.2 \pm 22.5^{\mathrm{a}}$ \\
\hline
\end{tabular}

Notes: ${ }^{a}<0.0001$ compared with control; ${ }^{b} p<0.001$ compared with 3 months after inoculation. of goblet cells, ${ }^{8}$ which are very sparse in the normal lacrimal sac. Correspondingly, with experimental dacryocystitis in the present study, there was a marked increase of secretory granules in the lacrimal sac epithelium. This probably contributed to the mucus hypersecretion that resided on the luminal surface and the mucopurulent exudate that was prominent at 3 months after inoculation. The thick layer of mucus on the lacrimal sac epithelium could trap the microorganisms, and it may act as a mechanical barrier against microbial invasion. The factors controlling the production of lacrimal sac-associated mucus are unknown, but it is possible that hypersecretion of mucus in the lacrimal sac can be linked with enhanced antimicrobial defense. However, excessive mucus production also contributes to insufficient

Table 2 Secretory granule density in the lacrimal sac epithelial dark cells over the diffuse lymphoid tissue. Contralateral lacrimal sacs not injected with Staphylococcus aureus served as controls

\begin{tabular}{ll}
\hline Condition & Density (granules per epithelial cell) \\
\hline Control & $10.2 \pm 8.5$ \\
I month after inoculation & $48.3 \pm 10.3^{\mathrm{a}}$ \\
3 months after inoculation & $92.9 \pm 20.8^{\mathrm{a}, \mathrm{b}}$ \\
\hline
\end{tabular}

Notes: a $P<0.0001$ compared with control; b $p<0.001$ compared with 3 months after inoculation. 


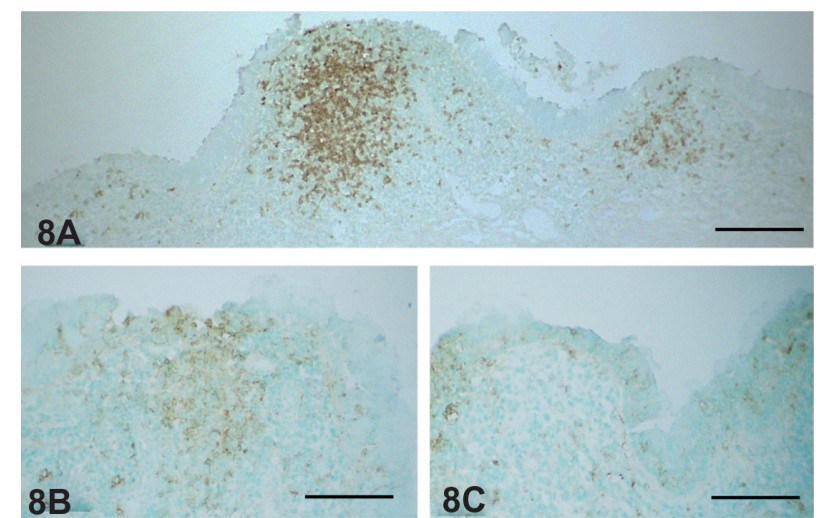

Figure 8 (A) CD20-positive B lymphocytes accumulated in the center of inflamed lacrimal sac lymphoid follicles I month after Staphylococcus aureus inoculation. Some of the B lymphocytes infiltrated into the diffuse lymphoid tissue adjacent to the follicle. IgA-positive plasma cells were more numerous in the inflamed lacrimal sac I month (B) after S. aureus inoculation than at 3 months (C).

Note: Bars $=60 \mu \mathrm{m}$.

gas exchange and keeps the microenvironment around the epithelium relatively anaerobic. ${ }^{16}$ This might contribute to the maintenance of chronic inflammation.

One of the main symptoms of the dacryocystitis is a refractory mucopurulent discharge. The control of mucus hypersecretion may thus contribute to the treatment of these diseases. Kaneko et $\mathrm{al}^{16}$ reported that clarithromycin, a macrolide antibiotic, prevents overproduction of mucin by inhibition of MUC5AC core protein, a major component of mucin, in a murine model of diffuse panbronchiolitis. As an extension to these studies, we will use our model of experimental rabbit dacryocystitis to analyze the extent of MUC5AC production in the lacrimal sac epithelium and the effect of macrolide treatment.

In the present study, it is of interest that the inflammatory cells diminished, and the proliferation of collagen fibers and fibrocytes became prominent in the lamina propria 3 months after bacterial inoculation. If the scarring of the inflamed lacrimal sac progresses, the obstruction of the lacrimal sac drainage might be induced at the late stage of the chronic dacryocystitis. Consistently, Paulsen et a ${ }^{17}$ reported that LDALT seems to be lost associated with the scarring of symptomatic dacryostenosis. Although the pathogenesis of the primary acquired nasolacrimal duct obstruction remains unclear, the present results might suggest that scar formation of the duct may precede the primary acquired nasolacrimal duct obstruction.

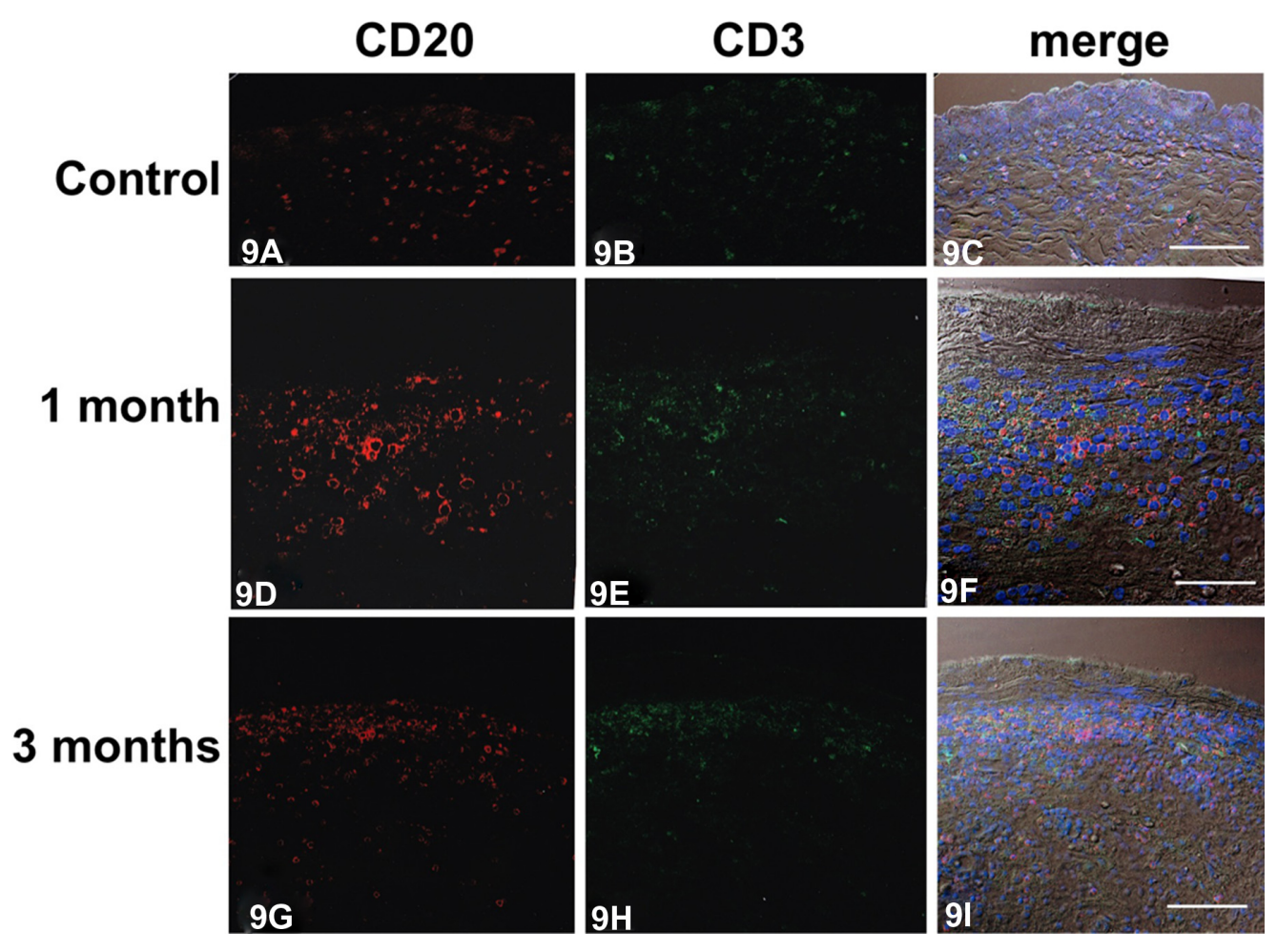

Figure 9 Immunofluorescent micrographs showing colocalization of CD20-positive B lymphocytes and CD3-positive T lymphocytes in the control (A-C) and inflamed lacrimal sac I month (D-F) and 3 months (G-I) after Staphylococcus aureus inoculation. In control tissue, a small number of CD20-positive (A, red) and CD3-positive lymphocytes (B, green) were codistributed (C) in the lamina propria. One month after inoculation, numerous CD20-positive (D, red) and CD3-positive lymphocytes (E, green) were coinfiltrated (F) into the lamina propria. Three months after inoculation, the numbers of CD20-positive (G, red) and CD3-positive (H, green) lymphocytes codistributed (I) were decreased compared with I month.

Notes: Bars $=65 \mu \mathrm{m}$; blue, diamidino-2-phenylindole-stained nuclei. 


\section{Disclosure}

The authors report no conflicts of interest in this work.

\section{References}

1. Garreis F, Gottschalt M, Schlorf T, et al. Expression and regulation of antimicrobial peptide psoriasin (S100A7) at the ocular surface and in the lacrimal apparatus. Invest Ophthalmol Vis Sci. 2011;52:4914-4922.

2. Perra MT, Serra A, Sirigu P, Turno F. A histochemical and immunohistochemical study of certain defense mechanisms in the human lacrimal sac epithelium. Arch Histol Cytol. 1995;58:517-522.

3. McDermott AM. The role of antimicrobial peptides at the ocular surface. Ophthalmic Res. 2009;41:60-75.

4. Garreis F, Gottschalt M, Paulsen FP. Antimicrobial peptides as a major part of the innate immune defense at the ocular surface. Dev Ophthalmol. 2010;45:16-22.

5. Garreis F, Schlorf T, Worlitzsch D, et al. Roles of human beta-defensins in innate immune defense at the ocular surface: arming and alarming corneal and conjunctival epithelial cells. Histochem Cell Biol. 2010;134:59-73.

6. Paulsen F, Pufe T, Schaudig U, et al. Protection of human efferent tear ducts by antimicrobial peptides. Adv Exp Med Biol. 2002;506:547-553.

7. Paulsen FP, Corfield AP, Hinz M, et al. Characterization of mucins in human lacrimal sac and nasolacrimal duct. Invest Ophthalmol Vis Sci. 2003;44:1807-1813.

8. Mauriello JA, Palydowycz S, Deluca J. Clinicopathologic study of lacrimal sac and nasal mucosa in 44 patients with complete acquired nasolacrimal duct obstruction. Ophthalmic Plast Reconstr Surg. 1992;8:13-21.
9. Knop E, Knop N. Lacrimal drainage-associated lymphoid tissue (LDALT): a part of the human mucosal immune system. Invest Ophthalmol Vis Sci. 2001;42:566-574.

10. Reimann SA, Wolfe AJ. Exposure to glycolytic carbon sources reveals a novel layer of regulation for the MALT regulon. Int $J$ Microbiol. 2011;2011:107023.

11. Okada K, Yamasoba T, Kiyono H. Craniofacial mucosal immune system: importance of its unique organogenesis and function in the development of a mucosal vaccine. Adv Otorhinolaryngol. 2011;72:31-36.

12. Brook I, Frazier EH. Aerobic and anaerobic microbiology of dacryocystitis. Am J Ophthalmol. 1998;125:552-554.

13. Maeda S, Ishikawa M, Abe T, et al. Lectin cytochemistry of the lacrimal sac epithelium in experimental dacryocystitis. Jpn J Ophthalmol. 1999; 43:69-74.

14. Pflugfelder SC, Jones D, Ji Z, et al. Altered cytokine balance in the tear fluid and conjunctiva of patients with Sjögren's syndrome keratoconjunctivitis sicca. Curr Eye Res. 1999;19:201-211.

15. Li DQ, Lokeshwar BL, Solomon A, et al. Regulation of MMP-9 production by human corneal epithelial cells. Exp Eye Res. 2001;73: 449-459.

16. Kaneko Y, Yanagihara K, Seki M, et al. Clarithromycin inhibits overproduction of muc5ac core protein in murine model of diffuse panbronchiolitis. Am J Physiol Lung Cell Mol Physiol. 2003;285: L847-L853.

17. Paulsen FP, Schaudig U, Maune S, Thale AB. Loss of tear ductassociated lymphoid tissue in association with the scarring of symptomatic dacryostenosis. Ophthalmology. 2003;110:85-92.
Clinical Ophthalmology

\section{Publish your work in this journal}

Clinical Ophthalmology is an international, peer-reviewed journal covering all subspecialties within ophthalmology. Key topics include: Optometry; Visual science; Pharmacology and drug therapy in eye diseases; Basic Sciences; Primary and Secondary eye care; Patient Safety and Quality of Care Improvements. This journal is indexed on Submit your manuscript here: http://www.dovepress.com/clinical-ophthalmology-journal

\section{Dovepress}

PubMed Central and CAS, and is the official journal of The Society of Clinical Ophthalmology (SCO). The manuscript management system is completely online and includes a very quick and fair peer-review system, which is all easy to use. Visit http://www.dovepress.com/ testimonials.php to read real quotes from published authors. 